\title{
Screening of organic micropollutants in raw and drinking water in the Yangtze River Delta, China
}

Hanwei Ren ${ }^{1}$, Rikard Tröger², Lutz Ahrens ${ }^{2}$, Karin Wiberg ${ }^{2 *}$ and Daqiang Yin ${ }^{*^{*}}$ (D)

\begin{abstract}
Background: The vast occurrence of organic micropollutants in surface waters has raised concerns about drinking water safety and public health. The Tai Hu Basin region in China, a typical developing and populous area, is facing the challenge of water pollution. To ensure drinking water safety, the knowledge on how treatment techniques and raw water quality affect the quality of finished water must be improved. The aim of the current study was to evaluate drinking water quality with respect to organic micropollutants and how the purity of the finished water depends on source water contamination and drinking water treatment strategies. Five drinking water treatment plants (DWTPs), using three different source waters in the Tai Hu River Basin, (i) Yangtze River, (ii) Wetland River Network, and (iii) Lake Tai Hu, were studied by analyzing 291 micropollutants in raw and finished water.

Results: Major differences in concentrations and composition profiles of organic micropollutants were observed between the source waters. Among the studied micropollutants, the dominating group was pesticides in the Wetland River Network and flame retardants in Yangtze. The total concentration of poly- and perfluoroalkyl substances (PFASs) in Tai Hu water was far higher than in the other samples. In total, 51 compounds were detected in the finished water, with an overall average total concentration of $730 \pm 160 \mathrm{ng} \mathrm{L}^{-1}$. The removal efficiency of the detected compounds in the DWTPs averaged $24 \pm 150 \%$, which highlights the major challenge for the DWTPs in removing the emerging organic micropollutants through current treatment processes.

Conclusions: Our study showed that if the source water contains high levels of PFASs and organophosphorus flame retardants, even advanced treatment procedures are inefficient in removing the micropollutants, and the finished drinking water may contain cumulative levels of organic micropollutants in the $\mu \mathrm{L}^{-1}$ range. On the other hand, if pesticides and pharmaceuticals dominate, a high overall treatment efficiencies may be obtained if advanced treatment techniques are used. The DWTPs are advised to use advanced treatment techniques or alternative water sources to guarantee the safety of drinking water. As surface water systems are highly impacted by upstream activities, efforts should also be made in the water sector for improving the surface water quality.
\end{abstract}

Keywords: Screening, Micropollutants, Tai Hu Basin, Source water, Drinking water, Removal efficiency, Flame retardants, PFASs, Pesticides, Industrial chemicals

\footnotetext{
*Correspondence: karin.wiberg@slu.se; yindq@tongji.edu.cn

1 Key Laboratory of Yangtze River Water Environment, Ministry

of Education, College of Environmental Science and Engineering, Tongji

University, Shanghai 200092, China

${ }^{2}$ Department of Aquatic Sciences and Assessment, Swedish University

of Agricultural Sciences (SLU), Box 7050, SE-750 07 Uppsala, Sweden
}

\section{Background}

Access to clean drinking water is an indispensable resource for people's daily lives and one of the United Nations' sustainable development goals. The presence of organic micropollutants in raw and finished drinking water has raised concerns about drinking water safety and public health, and there is a need to protect 
source water from ongoing and future contamination [1-4]. China, the most populous country on the globe, is extremely scarce in terms of per capita water resources. Therefore, how to ensure the safety of drinking water for the citizens is a great challenge that needs to be faced.

The Chinese population is unevenly distributed, with the main population distributed in the southeastern coastal areas. The Yangtze River, China's most important drinking water supply, enters the East China Sea $6300 \mathrm{~km}$ downstream the primary catchment area in the west. The river delta is centered on the City of Shanghai and comprises in total three provinces (Jiangsu, Zhejiang and Anhui) and 26 cities, which together constitutes an important population center and development area. The Yangtze River Delta occupies an important maritime transportation hub, with the Tai Hu River Basin covering most of the area. Therefore, agriculture, industry and trade activities are well developed in this region.

Surface water is the main water source of drinking water in Yangtze River Delta and Tai Hu River Basins. Since Yangtze River Delta is one of the most urbanized areas in China, with a population of 150 million (Tai Hu River Basin has 36 million people), this part of China exemplifies an area with extraordinarily high anthropogenic impact [5]. A number of studies have reported on the presence of organic micropollutants in surface waters in this region, e.g., antibiotics [6], phthalate esters [7], organochlorine pesticides [8,9], flame retardants [9-11] and poly- and perfluoroalkyl substances (PFASs) [12]. The occurrence of organic micropollutants has been reviewed in the Yangtze River showing that the pollutants were diluted due to an excess of water, which reduces the risks but does not entirely eliminate them [13]. Furthermore, PFASs [14], flame retardants [15] and some drug metabolites [16] have also been detected in finished drinking water, posing a health risks for citizens in this region.

Treatment of raw water at drinking water treatment plants (DWTPs) can reduce levels and complexity of the water. The removal efficiency is, however, highly dependent on treatment strategies [17], and conventional treatment has shown largely inefficient [18]. Although previous studies revealed the presence of a number of compound groups (e.g., PFASs) and pollution categories (e.g., pesticides and flame retardants) in both raw and drinking water from this region of China, the relative impact of groups of pollutants has not been thoroughly investigated.

The aim of the current study was to evaluate drinking water quality with respect to organic micropollutants and how the purity of finished water depends on source water contamination and drinking water treatment strategies. Five DWTPs in the Tai Hu River Basin, using three different water sources and various treatment strategies were studied. Almost 300 organic micropollutants were analyzed in water samples before and after DWTP treatment to evaluate the treatment efficiency for individual compounds. The organic micropollutants represented a broad variety of usage categories and compound groups, such as pharmaceuticals and personal care products (PCCPs), pesticides, PFASs, flame retardants, industrial chemicals, hormones, phthalates, and food additives. There was a large variability in pollutant levels and complexity in both raw and finished water, and conclusions could be drawn about the suitability of treatment options for different source water qualities.

\section{Methods and materials}

\section{Reference standards and chemicals}

In total, 291 organic micropollutants were targeted including pharmaceuticals $(n=108)$, pesticides $(n=99)$, PFASs $(n=18)$, flame retardants $(n=14)$, industrial chemicals $(n=14)$, hormones $(n=8)$, food additives $(n=6)$, phthalates $(n=5)$, personal care products $(n=4)$, surfactants $(n=4)$, fatty acids $(n=4)$, siloxanes $(n=2)$, stimulants $(n=2)$, isoflavones $(n=2)$, and contrast media $(n=1)$ (Table S1 in Additional file 1). Additionally, 21 isotope-labeled internal standards (ISs) were used (Table S2 in Additional file 1). The pesticide standards (native and isotope-labeled) were purchased from Teknolab Sorbent (Kungsbacka, Sweden) as accredited mixtures. Wellington Laboratories (Guelph, Canada) was the provider of the all PFAS standards. The remaining standards were bought from Sigma-Aldrich (Buchs, Switzerland) as solutions or crystalline of individual compounds, at analytical purity or higher, and were made into stock solutions in methanol or acetonitrile at a concentration of $1 \mathrm{mg} \mathrm{mL}^{-1}$.

Ultrapure water (Milli-Q) for solid-phase extraction (SPE) and mobile phases in the UPLC-system were generated in-house by a water purification system (Millipore; Bedford, USA). The buffers, acids and bases used for mobile phases were of LC-MS grade and purchased from Sigma-Aldrich (Buchs, Switzerland). The methanol and acetonitrile (LC-MS grade) were from Merck (Darmstadt, Germany) and the ethanol (AnalaR quality) was purchased from VWR International (Fontenay-sousBois, France).

\section{Sampling sites and sample collection}

Grab samples $(4 \mathrm{~L})$ of raw water $(n=1)$ and finished water ( $n=1$, named 'Drinking water' in the figures) were collected in September 2018 from five different drinking water treatment plants $(\mathrm{N} 1(\mathrm{~s}), \mathrm{N} 2(\mathrm{~s}), \mathrm{N} 3, \mathrm{~N} 4$, and $\mathrm{N} 5)$ located around Lake Tai $\mathrm{Hu}$ in the southeast of China and near the delta of the Yangtze River (Fig. 1). Additionally, two of the DWTPs were sampled a second time 


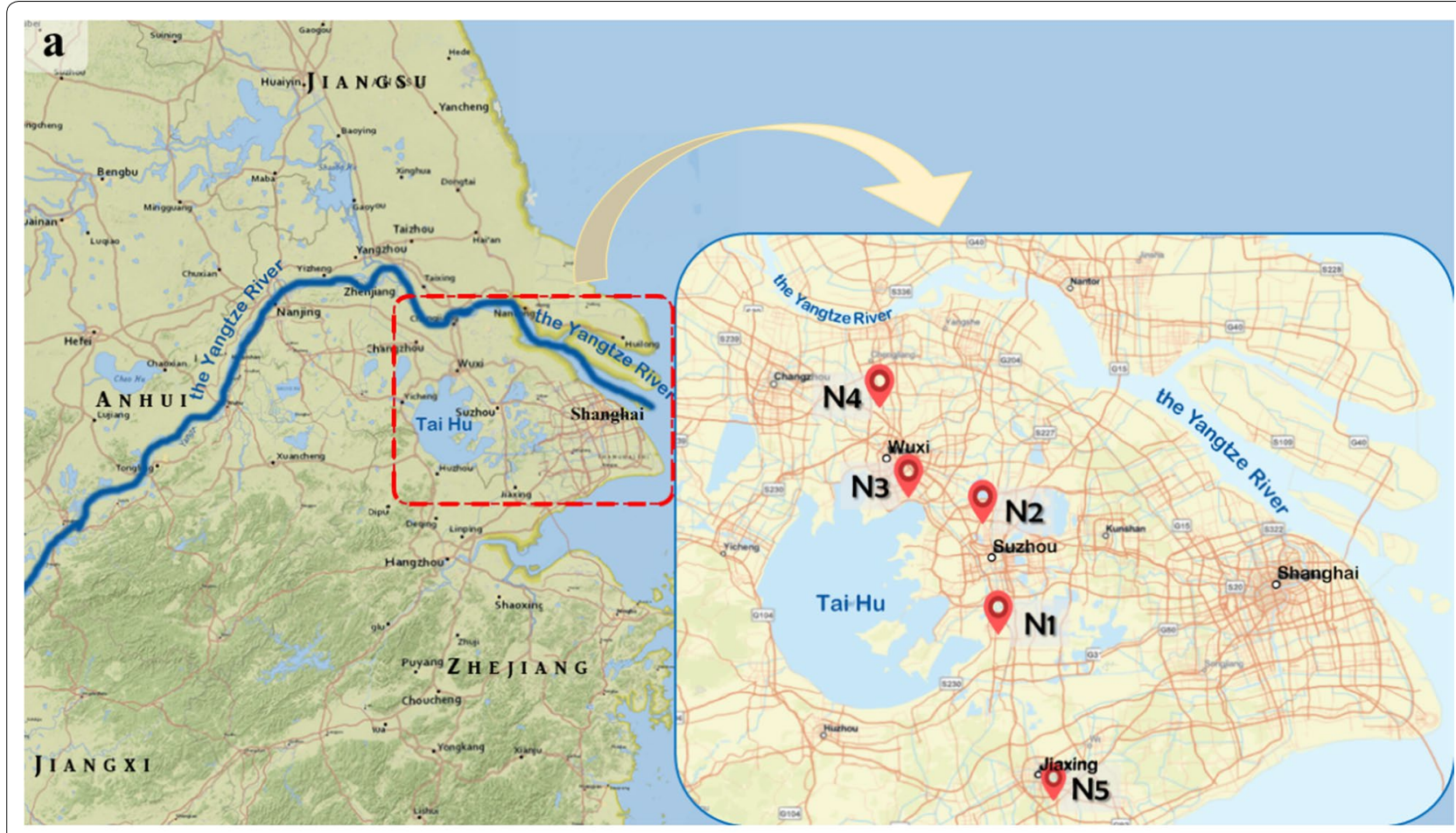

b

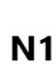

SP

N1
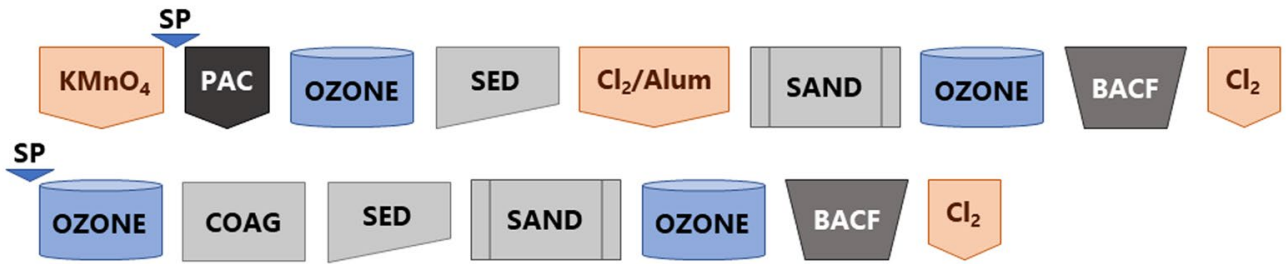

SP

N2
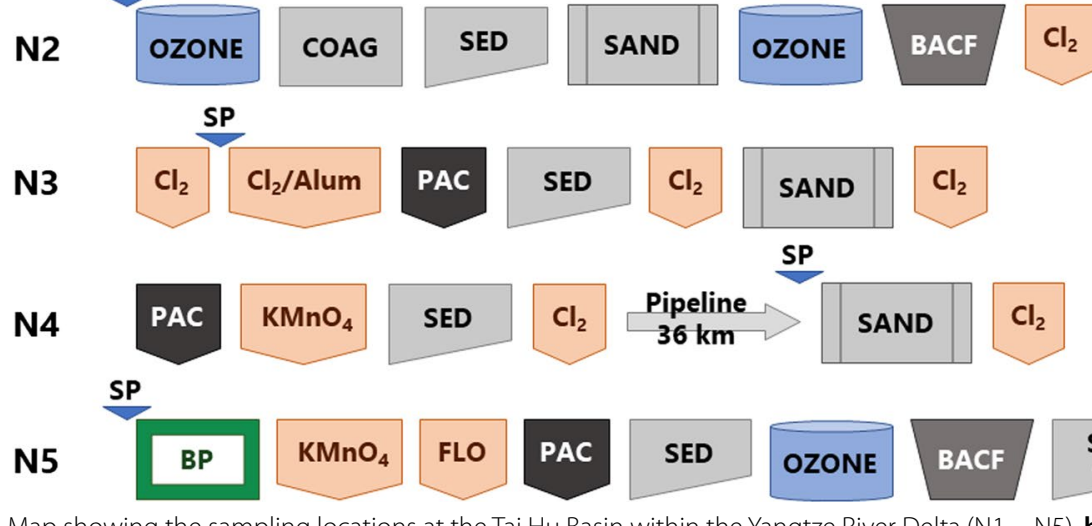

Fig. 1 a Map showing the sampling locations at the Tai Hu Basin within the Yangtze River Delta (N1 - N5). b DWTP treatment strategies and raw water sampling point. N1 - N5: 5 different DWTP. PAC powdered activated carbon, BACF biological activated carbon filter, OZONE ozone contactor, SED flocculation/sedimentation, SAND sand filter, $\mathrm{COAG}$ aluminum coagulation, $\mathrm{BP}$ biological pretreatment, $\mathrm{FLO}$ flocculant, $\mathrm{KMnO}_{4} / \mathrm{Cl}_{2} / \mathrm{alum}$ chemical additive, $S P$ sampling point of raw water

3 months later (December 2018; N1(w) and N2(w); duplicate samples at each site; $n=2+2 ; 4 \mathrm{~L}$ per sample). In the following, all N1 and N2 samples (September $(n=1)$ and December $(n=2)$; in total $n=3 \times 2$ (raw and finished) $\times 2$ (sites) $=12$ samples) are named as the Su Tai samples, and the N3, N4 and N5 samples are named the Wu Tai $(n=1 \times 2$ (raw and finished) $=2)$, the Yangtze $(n=1 \times 2=2)$ and river network $(n=1 \times 2=2)$ samples, respectively. The selected DWTPs provide drinking water to two cities in the Jiangsu Province and one city in the Zhejiang Province for a total of about 8 million people. Detailed information on the five DWTPs, including their source water and treatment strategies, are given in Table 1 and Fig. 1b. Note that the Yangtze DWTP 
Table 1 Detailed information of the sampling locations

\begin{tabular}{lllll}
\hline Sample name & Sampling site & Sampling date & Source water & Description of raw water \\
\hline N1(s) & Su Tai & $2018-09-30$ & Tai Hu & Water from Lake Tai Hu with pre-oxidation \\
N2(s) & Su Tai & $2018-09-30$ & Tai Hu & Water from Lake Tai Hu \\
N3 & Wu Tai & $2018-09-30$ & Tai Hu & Water from Lake Tai Hu with prechlorination \\
N4 & Yangtze & $2018-09-30$ & Yangtze River & Already treated at another DWTP, trans- \\
& & & ported via pipeline $(\sim 36$ km) \\
N5 & River network & $2018-09-30$ & River & River draining a wetland \\
N1 $(w)$ & Su Tai & $2018-12-01$ & Same as N1(s) & Same as N1(s) \\
N2(w) & Su Tai & $2018-12-01$ & Same as N2(s) & Same as N2(s) \\
\hline
\end{tabular}

${ }^{a}$ The treatment processes at the five DWTPs and the sampling points for raw and finished water in the DWTPs are shown in Fig. 1b

receives its raw water from another DWTP, i.e., finished water, but transported approximately $36 \mathrm{~km}$ through a pipeline.

All samples were collected directly from tap in 4-L pre-cleaned glass containers. The $\mathrm{pH}$ was immediately adjusted to 3 using hydrochloric acid solution. The samples were transported to the laboratory at Tongji University, China, within $8 \mathrm{~h}$ and stored at $4{ }^{\circ} \mathrm{C}$ until sample preparation. One field blank sample was prepared using Milli-Q water in the same type of glass container.

\section{Sample preparation}

The water samples were filtered through $0.7-\mu \mathrm{m}$ glass fiber filters (Grade GF/F circles, $47 \mathrm{~mm}$, Whatman, UK) including the field blank (Milli-Q water) control sample. Each sample was divided into four 1-L samples and extracted using SPE cartridges in series: Oasis ${ }^{\circledR}$ HLB 6cc Vac Cartridge (500 mg Sorbent per cartridge, Waters, USA) and Supelclean ${ }^{\mathrm{TM}}$ Coconut Charcoal SPE Tube ( $2 \mathrm{~g}$, $6 \mathrm{~mL}$, Sigma-Aldrich, USA). After loading and drying, the SPE cartridges were stored at $-40{ }^{\circ} \mathrm{C}$. One randomly selected pair of SPE cartridges (out of the four pairs; consisting of one HLB and one Cocoa Charcoal cartridge), i.e., in total $18 \times 2=36$ cartridges plus the field blank, were shipped to the Department of Aquatic Sciences and Assessment, Swedish University of Agricultural Sciences (SLU, Uppsala, Sweden) and stored at $4{ }^{\circ} \mathrm{C}$ until SPE elution. Before elution of the SPE cartridges, the 21 ISs were added (50 ng per IS) after dilution in Milli-Q water (approx. $40 \mathrm{~mL}$ ).

The two cartridges (HLB and Cocoa Charcoal) were eluted separately, first with $10 \mathrm{~mL}$ of a mixture of acetone and hexane $\left(\mathrm{V}_{\text {acetone }}: \mathrm{V}_{\text {hexane }}=1: 1\right)$ and then $10 \mathrm{~mL}$ of methanol [19] (Figure S1 in the Additional file 1). Each eluate was collected in a separate glass tube. The HLB and Cocoa Charcoal eluates were combined separately and evaporated under a gentle stream of nitrogen until approximately $4 \mathrm{~mL}$. The HLB and Cocoa Charcoal eluates were then combined and reduced to below $0.5 \mathrm{~mL}$ and transferred to an LC-MS vial. After each transfer step, the previous container was washed twice with methanol, which was also transferred to the next vial. The final extract was evaporated to less than $500 \mu \mathrm{L}$ in the vial and diluted to $1 \mathrm{~mL}$ with methanol (Figure S1 in Additional file 1).

\section{Instrumental analysis}

The instrumental analysis was performed as described previously by Tröger et al. [17]. In brief, a time-of-flight mass spectrometer (ToF) (Xevo G2-S, Waters, Micromass; Manchester, UK) coupled to a ultra-performance liquid chromatography (UPLC) system (Acquity H-Class with FTN injector; Waters, Milford, MA, USA) equipped with either an Acquity UPLC HSS T3-C18 column (positive ionization mode) or UPLC BEH-C18 column (negative mode) was used. The mobile phase was a gradient containing Milli-Q water and acetonitrile, and the injection volume was $10 \mu \mathrm{L}$. All data were collected in $\mathrm{MS}^{\mathrm{E}}$-mode, with a resolution of $\sim 30,000$ at $556.28 \mathrm{~m} / \mathrm{z}$ using leucine enkephalin for the lock spray and UNIFI v1.8.2 as the software for data collection and evaluation. Details of the targeted compounds and the analytical procedure (including IS used for each analyte) are given in Table S3 in Additional file 1.

\section{Quality assurance and method performance}

Calibration curves were run for each target compound with a concentration range of $0.1-120 \mathrm{ng} \mathrm{L}^{-1}$. The concentrations in the samples were mostly within this range, except a few data for tris(2-chloroethyl) phosphate (TCEP), triethyl phosphate (TEP), and butyl dihydrogen phosphate and a high fraction of the laurilsulfate data, which reached higher levels (Table S4 in Additional file 1). Data reported outside the calibration curve are marked in the table and should be interpreted with care.

The lowest level detected in the calibration curve was used as the method detect limit (MDL; Table S3 in Additional file 1). The results of the four duplicate samples 
(raw and drinking water for $\mathrm{N} 1(\mathrm{w})$ and $\mathrm{N} 2(\mathrm{w})$, respectively) were tested for similarity using two-sided Student's paired $t$ test and the data for compounds detected above the MDL. There was no significant difference between the duplicates at a $p$-level of $<0.05$ for any of the duplicates. The average relative standard deviation of the concentration data for the duplicate samples $(n=4$ and 68 detected compounds) were within the range $16-30 \%$.

The apparent recovery of the ISs, calculated from the relative responses of each IS in all samples, was on average 39\% ( $\pm 20 \%$ ) (Table S2 in Additional file 1). The levels in the field blank were generally low (on average $<1 \%$ of levels in samples), except for six compounds (laurilsulfate, lidocaine, cresyl diphenyl phosphate (CDP), triphenyl phosphate (TPHP), tris(2-butoxyethyl) phosphate (TBEP), laureth-5), for which occasionally higher levels were detected (35-75\%) (Table S4 in Additional file 1). The sample concentrations were corrected by subtracting the blank levels.

\section{Results and discussion Raw water quality}

In total, 68 (23\%) of the 291 targeted compounds were detected above the MDL in at least one raw water sample, and the number of detected compounds per sampling site ranged from 49 to 64 . The detected micropollutants represented a wide variety of compounds including pesticides $(n=27)$, pharmaceuticals $(n=15)$, PFASs $(n=10)$, organophosphorus flame retardants $(n=7)$, food additives $(n=2)$, industrial chemicals $(n=2)$, surfactants $(n=3)$, and a fatty acid $(n=1)$, stimulant $(n=1)$. The detected compounds and their concentrations at each sampling point are given in Table S4 in the Additional file 1.

The number of detected micropollutants on a category basis was rather similar between the five DWTPs (Fig. 2; raw water). This indicates a rather even distribution of emission sources in the Tai Hu Lake and the Yangtze River Delta area, with the exception of pesticides, which showed a higher number of detected compounds at the river network site. Overall, pesticides were the most detected pollutant category with on average $35 \% \pm 2 \%$ of all compounds detected (including all samples and sampling sites; $n=18$ ), followed by pharmaceuticals $(19 \% \pm 2 \%)$, PFASs $(17 \% \pm 2 \%)$, 'Others' $(16 \% \pm 2 \%$ : food additives, industrial chemicals, surfactants, stimulant and fatty acid), and flame retardants $(13 \% \pm 1 \%)$.

The total concentrations of the micropollutants in the raw water (Fig. 3) showed that the wetland river network was the most polluted site with respect to organic micropollutants (4 $000 \mathrm{ng} \mathrm{L}^{-1}$ ), followed by the Tai $\mathrm{Hu}$ Lake (1600 ng L $\mathrm{L}^{-1}$ for Su Tai and Wu Tai, respectively; using the same source water). As expected, Yangtze, with its raw water already treated through serval steps at another DWTP (Fig. 1b), showed the lowest total level (1000 ng L ${ }^{-1}$ ).

Overall, the most prevalent micropollutant was sucralose (food additive), which contributed to about onequarter of the total concentration in the water from $\mathrm{Su}$ Tai and Wu Tai (Fig. 3), and even more in the water from the Yangtze River (48\%; Fig. 3). In contrast, sucralose made up only $5 \%$ of the total concentration in the river network. Sucralose is frequently detected in rivers and lakes all over the world, with a reported concentration range of $0.08-1.0 \mu \mathrm{g} \mathrm{L}^{-1}$ in Europe [20], $18-175 \mathrm{ng} \mathrm{L}^{-1}$ in River Rhine [21], and 200-400 ng L ${ }^{-1}$ in northern China [22].

There were also other clear differences in the composition of the three source waters: Yangtze, the river network, and Tai $\mathrm{Hu}$ (Su Tai/Wu Tai). In the river network, the fraction made up by pesticides was $71 \%$ of the cumulative concentration, which was significantly higher than at the other three sites (8-23\%; Fig. 3). The cumulative concentration was $2800 \mathrm{ng} \mathrm{L}^{-1}$ in the river network, which is almost 10 times higher than the average concentrations at Tai $\mathrm{Hu}\left(340 \pm 100 \mathrm{ng} \mathrm{L}^{-1}\right)$ and 30 times higher than the Yangtze River raw water $\left(97 \mathrm{ng} \mathrm{L}^{-1}\right)$. The reason for the high dominance of pesticides in the river network can be attributed to the land use in the river catchment, which has a high proportion of agricultural areas. Moreover, although both Su Tai and Wu Tai are using Lake Tai Hu raw water, the Su Tai samples showed higher levels $\left(370 \pm 47 \mathrm{ng} \mathrm{L}^{-1} ; 23 \%\right.$ of total) than that at Wu Tai (130 ng L $\left.{ }^{-1} ; 8 \%\right)$. The pesticides with the highest concentrations at river network were carbendazim, imidacloprid, bentazon and azoxystrobin, which were detected at levels in the range $420-670 \mathrm{ng} \mathrm{L}^{-1}$. Overall (all sites), other common pesticides included bentazon $\left(85 \pm 47 \mathrm{ng} \mathrm{L}^{-1}\right)$, carbendazim $\left(60 \pm 40 \mathrm{ng} \mathrm{L}^{-1}\right), N, N$-diethyl-m-toluamide (DEET) $\left(38 \pm 32 \mathrm{ng} \mathrm{L}^{-1}\right)$, and atrazine (32 $\pm 11 \mathrm{ng} \mathrm{L}^{-1}$ ), which showed high detection frequency in source waters. These concentrations are corresponding or higher to those reported from Europe, where, e.g., DEET averaged $4.0 \mathrm{ng} \mathrm{L}^{-1}$ and atrazine averaged $2.2 \mathrm{ng}$ $\mathrm{L}^{-1}$ in rivers in southeast Spain [23], and the reported concentration ranges in River Rhine were $1-16 \mathrm{ng} \mathrm{L}^{-1}$ for bentazone, 7-105 $\mathrm{ng} \mathrm{L}^{-1}$ carbendazim, 6-120 $\mathrm{ng} \mathrm{L}^{-1}$ for DEET, and 1-6 ng L ${ }^{-1}$ for atrazine [21].

The number of detected PFASs differed between the sampling sites, with the lowest number at the Yangtze River site $(n=7 ; 14 \%$ of total number of detected compounds), whereas for other raw waters, the number of detected PFASs ranged from 9 to 10 (18-18\%), indicating upstream point sources of PFASs. The average concentration of $\sum$ PFASs in the Tai Hu raw water $\left(168 \pm 22 \mathrm{ng} \mathrm{L}^{-1}\right)$ was significantly higher (two-sided 

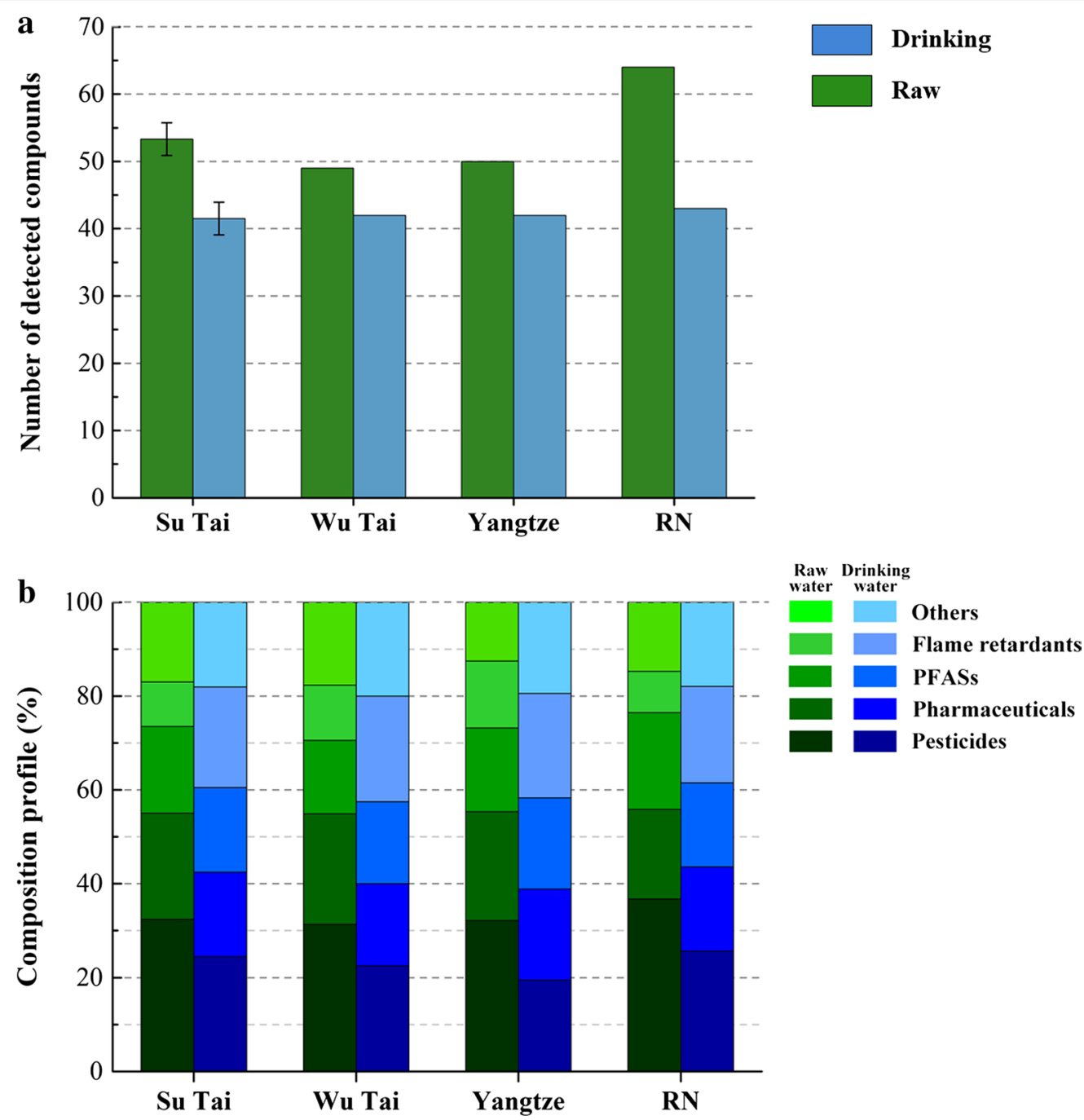

Fig. 2 a Total number of compounds detected above MDL in raw and drinking (finished) water at the different sites. Su Tai shows the average (and error bars) of samples from N1 and N2 ( $n=6: 2$ sites, 2 sampling occasions and 1 duplicate sample), while other bars show the result from $n=1$. $\mathbf{b}$ The fraction of the number of detected compounds (in relation to total) is shown on a compound category basis for each site. Compounds detected above MDL and their concentrations are given in Table $S 4$ in Additional file 1. RN river network

Student's $t$-test) than in the Yangtze River water (20 ng $\left.\mathrm{L}^{-1}\right)$, and the water from the wetland river network $\left(56 \mathrm{ng} \mathrm{L}^{-1}\right)(p=0.0003)$. Perfluorohexane sulfonic acid (PFHxS) was dominant in the Tai Hu water $(60 \%$ of the $\sum$ PFASs), whereas perfluorooctanoic acid (PFOA) was dominant in the water from wetland river network (63\%). On the other hand, PFHxS, PFOA and perfluorobutanoic acid (PFBA) were equally dominant in the Yangtze River water (22\%, 23\% and 27\%, respectively). The PFAS concentrations were generally comparable to other river water concentrations in China [24] and in the River Rhine watershed in Europe [25], but lower than other parts of the world such as Sweden [26], or India [27].
Organophosphorus flame retardants were the major group of compounds in the Yangtze and Wu Tai water, with cumulative concentrations of $290 \mathrm{ng} \mathrm{L}^{-1}$ and $405 \mathrm{ng}$ $\mathrm{L}^{-1}(28 \%$ and $26 \%)$, respectively. These levels are similar to Su Tai levels $\left(266 \pm 48 \mathrm{ng} \mathrm{L}^{-1}\right.$, but there the fraction of flame retardants was lower (16\%). Previous research has also reported frequent detection of organophosphorus flame retardants, e.g., in Yangtze River water [9] and river water in Sweden [28]. Since the use of brominated flame retardants is decreasing because of environmental and human health risks, organophosphorus flame retardants has become widely produced and used since the 1970s [10]. Phosphorus flame retardants have been detected in abiotic compartments as well as in living organisms 


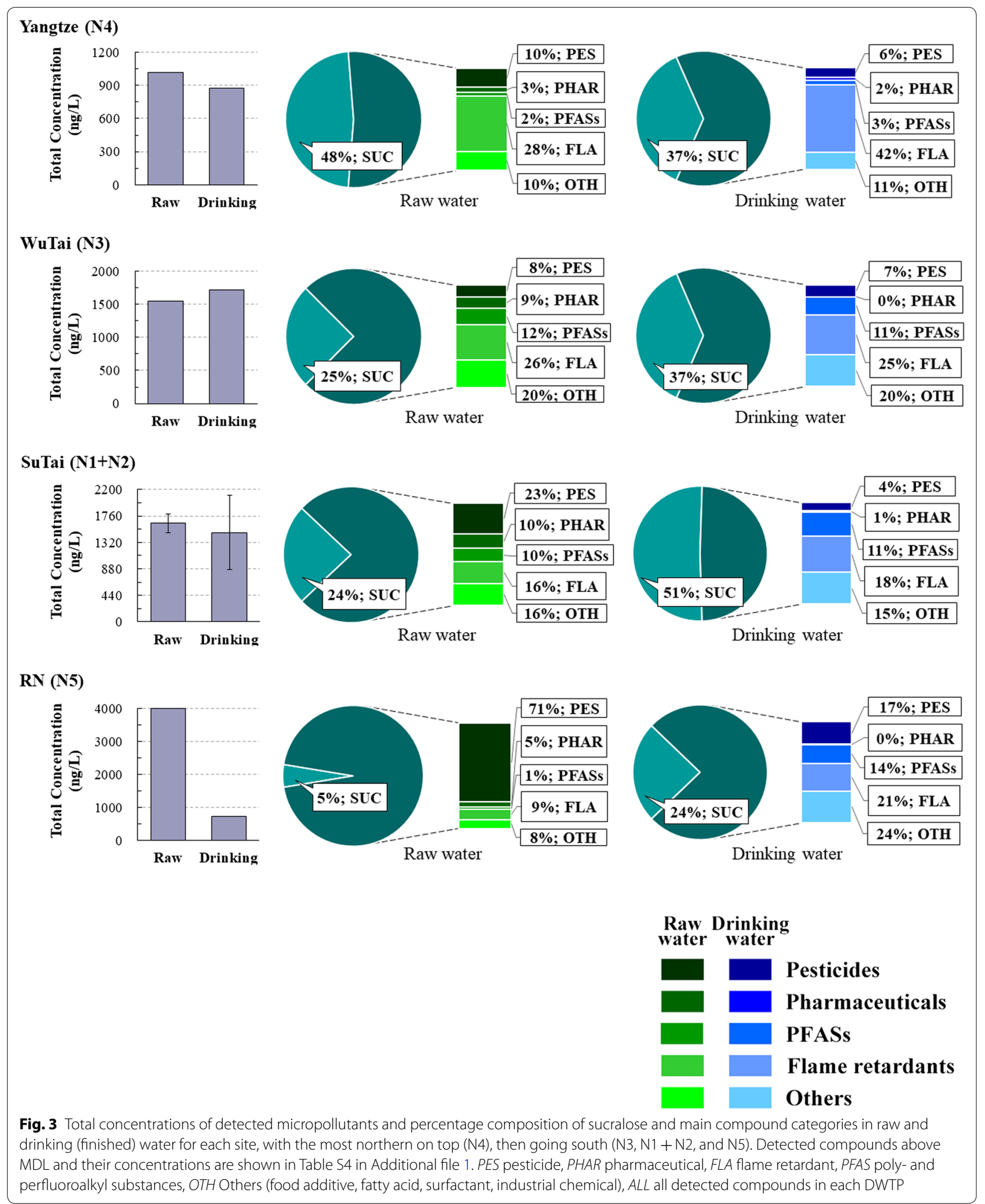


including humans $[29,30]$, indicating potential risk for environmental and human hazards.

The concentrations of the compound category 'Others', such as industrial chemicals (Table S4 in Additional file 1), were in the range $250-400 \mathrm{ng} \mathrm{L}^{-1}$. The most dominating compound was butyl dihydrogen phosphate, a surface-active agent used as, e.g., additive in lubricants and paints, with an overall (all sites) average concentration of $140 \pm 48 \mathrm{ng} \mathrm{L}^{-1}$.

An overall observation was that there was a composition profile change from north to south, i.e., going from Yangtze (N4), towards Wu Tai (N3), Su Tai (N1 + N2) and river network (N5), with an increasing proportion of pesticides and a decreasing proportion of flame retardants in the samples. This tendency shows that local emission sources and land use play a large role for the overall pollution. It also suggests that the Yangtze River in the north and the river network in the south may influence different parts of Lake Tai Hu.

\section{Drinking water quality}

The number of micropollutants detected above MDL decreased with on average $22 \%$ through the drinking water treatment process (Fig. 2a). In total, 51 compounds were detected in at least one sample including pesticides $(n=17)$, pharmaceuticals $(n=9)$, PFASs $(n=10)$, organophosphorus flame retardants $(n=7)$, food additives $(n=2)$, industrial chemicals $(n=2)$, surfactants $(n=3)$, and a fatty acid $(n=1)$. Similar to the raw water, the pesticide group was the most prevalent pollution category with on average 13 compounds per sample, followed by PFASs $(n=10)$, flame retardants $(n=7)$, pharmaceuticals $(n=6)$, and food additives $(n=1)$.

The total concentrations of the micropollutants mostly decreased, but also increased through the drinking water treatment process (Fig. 3, bar charts). The overall $(n=9)$ average total concentration was $730 \pm 160 \mathrm{ng} \mathrm{L}^{-1}$, and the concentration range was $720-2700 \mathrm{ng} \mathrm{L}^{-1}$. As in the raw water, sucralose dominated the concentration in every sample with a top concentration of $1900 \mathrm{ng} \mathrm{L}^{-1}$ (N1(s); $71 \%$ of total) and an overall average concentration of $630 \pm 520 \mathrm{ng} \mathrm{L}^{-1}$, which corresponds to a proportion of $30 \%$ or more in most of the samples. The average concentration is far higher than levels found in drinking water from northern China (110-160 ng L $\mathrm{L}^{-1}$ ) [31], and also higher than waste water treatment plant (WWTP) influents in some American cities (78-120 ng L ${ }^{-1}$ ) [32].

The cumulative concentrations of other detected micropollutants (without sucralose) were in the range of 540-1100 ng L ${ }^{-1}$ including all sites. The lowest value was $550 \mathrm{ng} \mathrm{L}^{-1}$ (river network), which is approximately 10 times higher than the micropollutant concentration in drinking water from northern Europe (Sweden)
[18], where a similar set of compounds were targeted (134 compounds and an overlap of $43 \%$ with the current study). Because of the relatively high removal rates of pesticides and pharmaceuticals, the PFASs, flame retardants and the category 'Others' were the dominant micropollutants in the drinking water (Fig. 3).

The concentration of $\sum$ PFASs ranged from 110 to $200 \mathrm{ng} \mathrm{L}^{-1}$ at N1 - N3 (Tai Hu Basin water; Su Tai/Wu Tai), and was $27 \mathrm{ng} \mathrm{L}^{-1}$ in the sample from N4 (Yangtze River water). The PFHxS was the dominant PFAS in Tai $\mathrm{Hu}\left(60-120 \mathrm{ng} \mathrm{L}^{-1}, \mathrm{~N} 1-\mathrm{N} 3\right)$, while PFBA was the highest PFAS in Yangtze River (11 $\left.\mathrm{ng} \mathrm{L}^{-1}\right)$ and PFOA was the highest in the river network water $\left(54 \mathrm{ng} \mathrm{L}^{-1}\right)$. The PFAS concentrations in drinking water were generally higher than those in drinking water from USA, Brazil, Spain, and France [33-35].

Flame retardants was the main micropollutant category in drinking water from the Yangtze River (370 ng $\mathrm{L}^{-1} ; 42 \%$ of total) and generally contributed to more than $20 \%$ of the total concentration of all compounds in the drinking water at all sites, except for N1(s). Overall (all sites), the compounds with the highest concentrations were TEP (average $120 \mathrm{ng} \mathrm{L}^{-1}$ ) and TCEP (average $96 \mathrm{ng}$ $\mathrm{L}^{-1}$ ). These two organophosphorus flame retardants were at almost the same concentration as levels reported from the Netherlands (48-100 ng L ${ }^{-1}$ ) [16]. Another compound with high concentration was butyl dihydrogen phosphate (average $130 \mathrm{ng} \mathrm{L}^{-1}$ ), an industrial chemical, rarely (if ever) reported as present in drinking water before. The occurrence of micropollutants in drinking water is dependent on the quality of water source (Fig. 3), as well as on the treatment efficiency at the DWTP. In the next section, the impact of the treatment process is examined.

\section{Removal efficiency}

The removal efficiencies for all compounds at all DWTPs are given in Table S5 in Additional file 1 and are illustrated in Fig. 4. The overall average removal efficiency of all compounds averaged $24 \pm 149 \%(\mathrm{~N} 1-\mathrm{N} 5, n=9$, including the two extra samples and the duplicates at $\mathrm{N} 1+\mathrm{N} 2$ ). The removal of pesticides averaged $65 \pm 50 \%$ and the pharmaceuticals $74 \pm 49 \%$, while the removal of other compound categories was significantly lower $\left(p<10^{-8}\right.$, two-sided Student's $t$-test), with average efficiencies of $3 \pm 99 \%$ for 'Others' (food additives, surfactant, industrial chemicals, fatty acid), $-1 \pm 13 \%$ for flame retardants, and $-140 \pm 329 \%$ for PFASs. Thus, the flame retardants showed negative treatment efficiencies, which means they boosted through the treatment process. Similarly, the removal of PFASs was often inefficient or even negative at the investigated DWTPs. Previous studies have shown that conventional treatment 

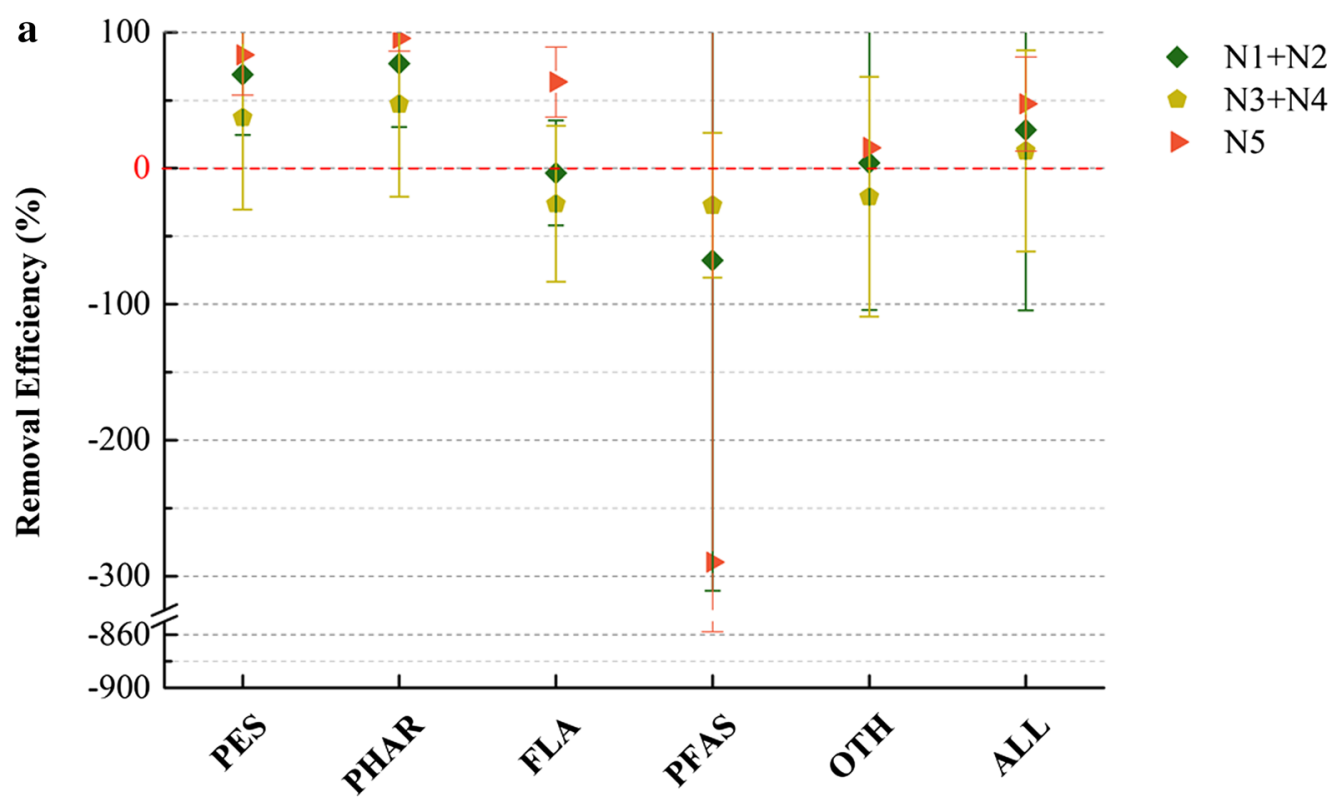

b

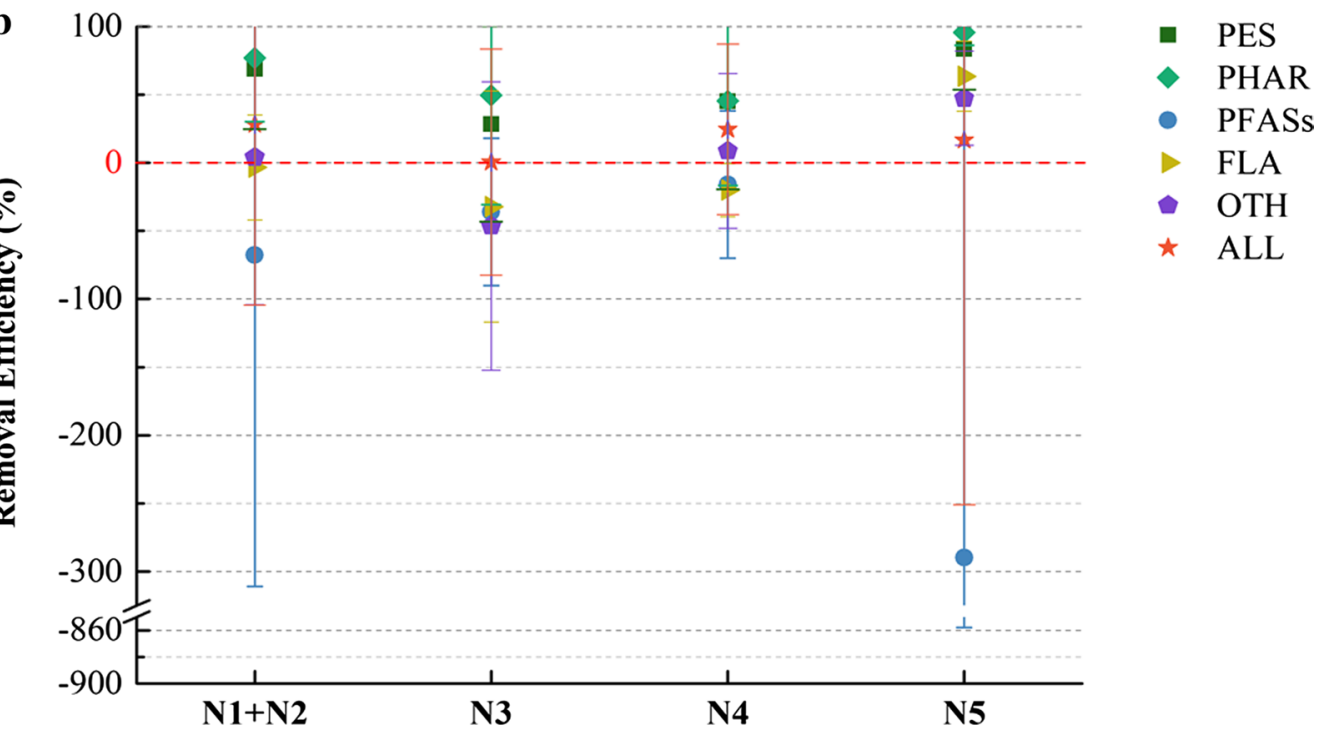

Fig. 4 Treatment efficiency for a each compound category for DTWPs with similar treatment strategy and b DWTPs with similar treatment strategy per compound category. PES pesticide, PHAR pharmaceutical, FLA flame retardant, PFAS poly-and perfluoroalkyl substances, OTH Others (food additive, fatty acid, surfactant, industrial chemical), ALL all detected compounds in each DWTP

techniques are inefficient in removing PFASs [36]. Negative removal efficiency may be explained by timedependent concentrations and the lag time between sampling raw and finished water, degradation of PFAS precursors to persistent PFASs [37] and desorption/ breakthrough of PFASs from granular activated carbon (GAC) or other filter types within the DWTP [38]. GAC and anion exchange filters are currently used for removal of PFASs in DWTPs; however, development of new treatment options is needed, in particular for the shorter chain PFASs [38-40].

There were no significant differences in the removal efficiencies of all detected compounds among the five DWTP $(p>0.06$, two-sided Student's $t$-test $)$, although the DWTPs used different treatment strategies (Figs. 1b, 4a). It should be noted that three of the DWTPs use ozonation, i.e., advanced treatment technology; yet removal efficiencies are moderate to 
low. This demonstrates the major challenge in removing organic micropollutants through modern drinking water treatment technologies.

The removal efficiencies among different treatment strategies are shown in Fig. 4b. N1, N2 and N5 have ozone treatment and biological activated carbon filter (BACF) in contrast to N3 and N4. Additionally, N5 has an extra biological pretreatment step as compared to $\mathrm{N} 1-\mathrm{N} 4$. The removal efficiencies of the pesticides and the pharmaceuticals at $\mathrm{N} 3+\mathrm{N} 4$ were significantly lower than at $\mathrm{N} 1+\mathrm{N} 2$ and N5 $(p<0.05$, two-sided Student's $t$ test), which shows that the conventional treatment (sedimentation, filtration and disinfection) cannot remove pesticides and pharmaceuticals in water effectively. On the other hand, N1 + N2 and N5 with their more advanced treatment process (including ozonation) were successful with these two substance groups. This is also illustrated for N5 in Fig. 3, with a fivefold drop in total concentration from raw to drinking water (from 3990 to $720 \mathrm{ng}$ $\mathrm{L}^{-1}$, going from $76 \%$ 'pesticides + pharmaceuticals' of total to $17 \%)$. The removal efficiency of flame retardants in N5 was also rather efficient, with significantly higher efficiency than $\mathrm{N} 1+\mathrm{N} 2$ and $\mathrm{N} 3+\mathrm{N} 4(p<0.02$, two-sided Student's $t$-test). This suggests that the biological treatment has the ability to remove flame retardants in water.

\section{Potential human health risks of sucralose}

The artificial sweetener sucralose was the dominant micropollutant in both raw and drinking water and this may cause human health concern. Sucralose is widely used in the food industry since the 1970s, because of its sweet taste and stability. Sucralose has been shown to be a persistent, ubiquitously occurring environmental pollutant $[20,41]$ and is commonly detected in wastewater, surface water, groundwater and drinking water $[20,22$, 42]. It has been tested for toxicity, and there are some reports on that exposure may led to negative effects, e.g., on locomotion and physiological behavior of crustaceans [43]. However, there is a lack of studies focusing on chronical and low-dose effects $[44,45]$. Rahn et al. [46] found that sucralose can degrade and produce chloropropanols (3-monochloropropanediol and 1,2- and 1,3-dichloropropanols) under thermal decomposition. These metabolites are known as a potentially toxic class of compounds that may cause cancer [47]. Another study indicated that ingestion of sucralose may affect the glucose metabolism of obese people who rarely use nonnutritive sweeteners [48]. More studies on the toxicity of sucralose are needed, and it is also important to consider the potential toxicity of its metabolites, which, e.g., are formed during cooking under high temperature [49], a common practice in China.

\section{Conclusions}

Our study has shown that finished (drinking) water quality is dependent both on source water quality and treatment strategies. If the source water contains high levels of PFASs, flame retardants and other pollutants (e.g., sucralose and butyl dihydrogen phosphate), even advanced treatment procedures, including, e.g., ozonation, are inefficient and the finished water may contain cumulative micropollutant levels in the $\mu \mathrm{g} \mathrm{L}^{-1}$ range. On the other hand, if the dominating pollution categories are pesticides and pharmaceuticals, high overall treatment efficiencies can be obtained if advanced treatment steps are used, while DWTPs using conventional treatment likely have poor removal of organic micropollutants. DWTPs have the challenging task of purifying "reused" water, i.e., water that was contaminated by organic micropollutants originating from upstream effluents, such as WWTP and industrial effluents. For improved overall drinking water quality, it is imperative that water quality comes into focus in the water sector as a whole. DWTPs should pay attention to the characteristics of their source water and make efforts in using efficient treatment processes, enhancing the quality of finished water. In our study, organic micropollutants were found in drinking water at cumulative levels from $0.7 \mu \mathrm{g} \mathrm{L}{ }^{-1}$ up to $2.7 \mu \mathrm{g} \mathrm{L}{ }^{-1}$, clearly demonstrating the challenge with organic micropollutants in the water from source to tap. Thus, advanced drinking water treatment techniques or alternative drinking water source areas are needed to guarantee safety of drinking water. Overall, more data on human health risks associated with a continuous intake of potentially hazardous organic micropollutants and their mixtures (cocktails) are needed to support risk assessment activities for drinking water.

\section{Supplementary information}

Supplementary information accompanies this paper at https://doi. org/10.1186/s12302-020-00342-5.

Additional file 1. Additional figure and tables.

\section{Abbreviations}

DWTP: Drinking water treatment plant; WWTP: Waste water treatment plant; PCCPs: Pharmaceuticals and personal care products; ISs: Internal standards; UPLC: Ultra-performance liquid chromatography; ToF MS: Time-of-flight mass spectrometer; MDL: Method detect limit; SPE: Solid-phase extraction; PAEs: Phthalate esters; OCPs: Organochlorine pesticides; PFASs: Poly- and perfluoroalkyl substances; CDP: Cresyl diphenyl phosphate; TPHP: Triphenyl phosphate; TBEP: Tris(2-butoxyethyl) phosphate; TCEP: Tris(2-chloroethyl) phosphate; TEP: Triethyl phosphate; DEET: N,N-Diethyl-m-toluamide; PFHxS: Perfluorohexane sulfonic acid; PFOA: Perfluorooctanoic acid; PFBA: Perfluorobutanoic acid; GAC : Granular activated carbon; BACF: Biological activated carbon filter.

\section{Acknowledgements}

This work was supported by the National Major Science and Technology Project of China (2018ZX07701001-22), the National Natural Science Foundation of China (Grant Number 21876136), and the Swedish Research Council 
for Sustainable Development (Formas) through the DANTE and LakePOPs projects (Grant Numbers 2018-02256 and 2016-01173).

\section{Authors' contributions}

HR was the major contributor in experiments, data analysis and manuscript writing. HR and DY designed the study. RT helped with the instrumental analysis, micropollutant quantification, and quality assurance/quality control of data. KW and LA contributed to data evaluation and manuscript writing. KW and DY contributed to improvements of the manuscript. All authors read and approved the final manuscript.

\section{Funding}

This work was supported by the National Major Science and Technology Project of China (2018ZX07701001-22), the National Natural Science Foundation of China (Grant Number 21876136), and the Swedish Research Council for Sustainable Development (Formas) through the DANTE and LakePOPs projects (Grant Numbers 2018-02256 and 2016-01173).

\section{Availability of data and materials}

Not applicable.

\section{Ethics approval and consent to participate}

Not applicable.

\section{Consent for publication}

Not applicable.

\section{Competing interests}

The authors declare that they have no competing interests.

Received: 27 December 2019 Accepted: 18 April 2020

Published online: 29 April 2020

\section{References}

1. Schwarzenbach RP et al (2006) The challenge of micropollutants in aquatic systems. Science 313(5790):1072-1077

2. Reemtsma T et al (2016) Mind the gap: persistent and mobile organic compounds water contaminants that slip through. Environ Sci Technol 50(19):10308-10315

3. Benotti MJ et al (2008) Pharmaceuticals and endocrine disrupting compounds in US drinking water. Environ Sci Technol 43(3):597-603

4. Niimi AJ, Oliver BG (1983) Biological half-lives of polychlorinated biphenyl (PCB) congeners in whole fish and muscle of rainbow trout (Salmo gairdneri). Can J Fish Aquat Sci 40:1388-1394

5. Tiehm A et al (2020) Tai Hu (China): water quality and processes—from the source to the tap. Sci Total Environ 712:5

6. Yan C et al (2013) Antibiotics in the surface water of the Yangtze Estuary: occurrence, distribution and risk assessment. Environ Pollut 175:22-29

7. Chen $\mathrm{H}$ et al (2019) Distribution, source, and environmental risk assessment of phthalate esters (PAEs) in water, suspended particulate matter, and sediment of a typical Yangtze River Delta City, China. Environ Sci Pollut Res Int 26(24):24609-24619

8. Jin X et al (2019) Risk assessment of organochlorine pesticides in drinking water source of the Yangtze River. Ecotoxicol Environ Saf 182:109390

9. Peng $Y$ et al (2018) Screening hundreds of emerging organic pollutants (EOPs) in surface water from the Yangtze River Delta (YRD): occurrence, distribution, ecological risk. Environ Pollut 241:484-493

10. Zhu B et al (2013) Conventional and emerging halogenated flame retardants (HFRs) in sediment of Yangtze River Delta (YRD) region, East China. Chemosphere 93(3):555-560

11. Su G et al (2014) Occurrence of additive brominated flame retardants in aquatic organisms from Tai Lake and Yangtze River in Eastern China, 2009-2012. Chemosphere 114:340-346

12. Zheng B et al (2017) Distribution characteristics of poly- and perfluoroalkyl substances in the Yangtze River Delta. J Environ Sci (China) 61:97-109

13. Floehr T et al (2013) Solution by dilution?-A review on the pollution status of the Yangtze River. Environ Sci Pollut Res 20(10):6934-6971
14. Qu Y et al (2019) Poly- and perfluoroalkyl substances in a drinking water treatment plant in the Yangtze River Delta of China: temporal trend, removal and human health risk. Sci Total Environ 696:133949

15. Richardson SD (2003) Disinfection by-products and other emerging contaminants in drinking water. Trac-Trends Anal Chem 22(10):666-684

16. Houtman CJ et al (2019) Statistical analysis of a large set of semi-quantitative GC-MS screening data to evaluate and prioritize organic contaminants in surface and drinking water of the Netherlands. Sci Total Environ 697:133806

17. Troger R et al (2019) A case study of organic micropollutants in a major Swedish water source-removal efficiency in seven drinking water treatment plants and influence of operational age of granulated active carbon filters. Sci Total Environ 706:135680

18. Troger $\mathrm{R}$ et al (2018) Micropollutants in drinking water from source to tap-method development and application of a multiresidue screening method. Sci Total Environ 627:1404-1432

19. Escher Bl et al (2014) Benchmarking organic micropollutants in wastewater, recycled water and drinking water with in vitro bioassays. Environ Sci Technol 48:1940-1956

20. Lange FT, Scheurer M, Brauch H-J (2012) Artificial sweeteners-a recently recognized class of emerging environmental contaminants: a review. Anal Bioanal Chem 403(9):2503-2518

21. Ruff M et al (2015) Quantitative target and systematic non-target analysis of polar organic micro-pollutants along the river Rhine using highresolution mass-spectrometry-identification of unknown sources and compounds. Water Res 87:145-154

22. Morlock GE, Schuele L, Grashorn S (2011) Development of a quantitative high-performance thin-layer chromatographic method for sucralose in sewage effluent, surface water, and drinking water. J Chromatogr A 1218(19):2745-2753

23. Robles-Molina J et al (2014) Monitoring of selected priority and emerging contaminants in the Guadalquivir River and other related surface waters in the province of Jaen, South East Spain. Sci Total Environ 479-480:247-257

24. Lu Z et al (2015) Occurrence and trends in concentrations of perfluoroalkyl substances (PFASs) in surface waters of eastern China. Chemosphere 119:820-827

25. Moller A et al (2010) Distribution and sources of polyfluoroalkyl substances (PFAS) in the River Rhine watershed. Environ Pollut 158(10):3243-3250

26. Gobelius L et al (2018) Per- and polyfluoroalkyl substances in swedish groundwater and surface water: implications for environmental quality standards and drinking water guidelines. Environ Sci Technol 52(7):4340-4349

27. Sharma BM et al (2016) Perfluoroalkyl substances (PFAS) in river and ground/drinking water of the Ganges River basin: emissions and implications for human exposure. Environ Pollut 208:704-713

28. Gustavsson J et al (2019) Seasonal trends of legacy and alternative flame retardants in river water in a boreal catchment. Sci Total Environ 692:1097-1105

29. Wei GL et al (2015) Organophosphorus flame retardants and plasticizers: sources, occurrence, toxicity and human exposure. Environ Pollut 196:29-46

30. Greaves AK, Letcher RJ (2017) A review of organophosphate esters in the environment from biological effects to distribution and fate. Bull Environ Contam Toxicol 98(1):2-7

31. Gan Z et al (2013) A novel solid-phase extraction for the concentration of sweeteners in water and analysis by ion-pair liquid chromatographytriple quadrupole mass spectrometry. J Chromatogr A 1274:87-96

32. Currens BJ et al (2019) Use of acetaminophen and sucralose as coanalytes to differentiate sources of human excreta in surface waters. Water Res 157:1-7

33. Hu XC et al (2016) Detection of poly- and perfluoroalkyl substances (PFASs) in US drinking water linked to industrial sites, military fire training areas, and wastewater treatment plants. Environ Sci Technol Lett 3(10):344-350

34. Ericson I et al (2009) Levels of perfluorinated chemicals in municipal drinking water from Catalonia, Spain: public health implications. Arch Environ Contam Toxicol 57(4):631-638

35. Schwanz TG et al (2016) Perfluoroalkyl substances assessment in drinking waters from Brazil, France and Spain. Sci Total Environ 539:143-152 
36. Post GB, Cohn PD, Cooper KR (2012) Perfluorooctanoic acid (PFOA), an emerging drinking water contaminant: a critical review of recent literature. Environ Res 116:93-117

37. Butt CM, Muir DCG, Mabury SA (2014) Biotransformation pathways of fluorotelomer-based polyfluoroalkyl substances: a review. Environ Toxicol Chem 33(2):243-267

38. McCleaf P et al (2017) Removal efficiency of multiple poly- and perfluoroalkyl substances (PFASs) in drinking water using granular activated carbon (GAC) and anion exchange (AE) column tests. Water Res 120:77-87

39. Ateia $\mathrm{M}$ et al (2019) Efficient PFAS removal by amine-functionalized sorbents: critical review of the current literature. Environ Sci Technol Lett 6(12):688-695

40. Gagliano E et al (2020) Removal of poly- and perfluoroalkyl substances (PFAS) from water by adsorption: role of PFAS chain length, effect of organic matter and challenges in adsorbent regeneration. Water Res 171:31

41. Soh L et al (2011) Fate of sucralose through environmental and water treatment processes and impact on plant indicator species. Environ Sci Technol 45(4):1363-1369

42. Buerge IJ et al (2009) Ubiquitous occurrence of the artificial sweetener acesulfame in the aquatic environment: an ideal chemical marker of domestic wastewater in groundwater. Environ Sci Technol 43(12):4381-4385
43. Hjorth M, Hansen $J$, Camus L (2010) Short-term effects of sucralose on Calanus finmarchicus and Calanus glacialis in Disko Bay, Greenland. Chem Ecol 26(5):385-393

44. Grotz VL et al (2017) A 12-week randomized clinical trial investigating the potential for sucralose to affect glucose homeostasis. Regul Toxicol Pharmacol 88:22-33

45. Berry $C$ et al (2016) Sucralose non-carcinogenicity: a review of the scientific and regulatory rationale. Nutr Cancer 68(8):1247-1261

46. Rahn A, Yaylayan VA (2010) Thermal degradation of sucralose and its potential in generating chloropropanols in the presence of glycerol. Food Chem 118(1):56-61

47. Farooqui AA (2015) High calorie diet and the human brain. Springer, Berlin. https://doi.org/10.1007/978-3-319-15254-7

48. Pepino MY et al (2013) Sucralose affects glycemic and hormonal responses to an oral glucose load. Diabetes Care 36(9):2530-2535

49. Pu GW et al (2019) Study on the use of cooking oil in chinese dishes. Int J Environ Res Public Health 16(18):7

\section{Publisher's Note}

Springer Nature remains neutral with regard to jurisdictional claims in published maps and institutional affiliations.

\section{Submit your manuscript to a SpringerOpen ${ }^{\circ}$ journal and benefit from:}

- Convenient online submission

- Rigorous peer review

- Open access: articles freely available online

- High visibility within the field

- Retaining the copyright to your article

Submit your next manuscript at $\boldsymbol{\nabla}$ springeropen.com 